\title{
Football Without Football: Creativity in German Football Coverage by TV Broadcasters and Clubs During the Coronavirus Crisis
}

\author{
Christiana Schallhorn \\ Jessica Kunert \\ Johannes Gutenberg University of Mainz \\ University of Hamburg
}

\begin{abstract}
During the COVID-19 pandemic, TV broadcasters and clubs were challenged to provide alternative formats and content for fans of Germany's favorite sport, football [soccer]. Thus, they emulated matchdays and created a Bundesliga feeling in new ways. The authors focus on this alternative creative sports coverage during the Coronavirus crisis and consider the effect on the audience. TV broadcasters, for instance, recreated Bundesliga matchdays through broadcasting historical matches, sticking with the original fixtures from before the crisis, while offering renewed commentary. Clubs conducted the Bundesliga Home Challenge, that is, FIFA20 videogame matches with their professional and eSport players, covering these matches on Twitter and their website. The authors argue that these efforts of keeping up the beloved structure of daily sports events satisfy social and entertaining belongings that are normally continually recreated through watching and talking about live sports events. Moreover, they discuss the possible sustainability of these innovative ways of sport communication.
\end{abstract}

Keywords: broadcasting, football clubs, journalism, sport media

\section{No More Football: What Now?}

Everything was well in Germany's world of sport at the beginning of March 2020: football [soccer] stadiums were full of spectators, and any change from the regularly scheduled programming was unimaginable, even unthinkable. Only a few days later, the Coronavirus dictated the matchday. Thus, the emotionally highly charged derby between Borussia Mönchengladbach and 1. FC Köln took place as a so-called ghost match without spectators, the last one before football was shut down completely. But on that decisive day, even though fans were not allowed 
inside the stadium, several hundred of them gathered in front of the stadium anyway, unwilling to let this large piece of their everyday life break away. They were hanging on to what was normal in Germany up to that day, namely, crowded stadiums, packed sports bars, and occupied TV sets, all in the name of Germany's most favorite sport.

Germans, who regard their country as a football nation, need their daily dose of football. And they usually get it, because football competitions and matchdays are distributed throughout the week. On Mondays, games of the second Bundesliga take place. Tuesdays and Wednesdays are reserved for the Champions League games, where the best teams in Europe compete for the cup. On Thursdays, the Europa League matches are on the schedule, and Fridays to Sundays are dedicated to the Bundesliga. In addition, qualifying matches for various national and international tournaments, national knockout competition DFB-Pokal (German Football Association Cup) matches, as well as European and world championships, provide entertainment in everyday football. This tight schedule demonstrates that football in Germany is not only an essential part of everyday life, but also structures it. In other words, "the fan's daily and weekly agenda is determined by his relationship with the football club" (Porat, 2010, p. 277).

Furthermore, football has an enormous social function in Germany: it connects people of different ages, origins, and social classes. Club football, especially, creates a common identity and generates a sense of community, and some people feel like they are part of a large football family (Ismer, 2011). The reporting and coverage associated with the competitions are a popular topic to talk about with family, friends, relatives, neighbors, colleagues, and even people you have never met before. These shared encounters have a unifying effect like hardly anything else, whether experienced in person (e.g., Dixon, 2014) or online (Lawrence \& Crawford, 2019). First and foremost, social media provide a space for sports fans to interact with each other as well, as with athletes and clubs (Sanderson \& Kassing, 2014), thus, allowing fans to come together as a tight-knit community, even if they might support their favorite Bundesliga team from halfway around the world (Kunert, 2019). Last but not least, football provides entertainment, enjoyment, and a way out of everyday problems and duties (Wann, Grieve, Zapalac, \& Pease, 2008).

With the absence of sporting competitions, many of these needs for solidarity and community, social integration and communication, entertainment and escapism cannot be satisfied during the Coronavirus crisis. But satisfying these needs became all the more important, especially because of numerous restrictions and limitations due to Coronavirus interventions. This exceptional state does not only confront fans with special challenges, but also has an impact on journalists, sports broadcasters and media, and clubs. For the latter, it is also a major challenge to deal with the situation because they rely on the interaction and exchange with their fans to maintain fan engagement. Consequently, all of these actors need to be creative, especially concerning two central questions. First, how can they continue to fill previous broadcasting times, (online) magazines, or newspaper pages with sports coverage, even though there are no current results, events, or interviews to reportwhich is what sports coverage normally is all about. Second, how can they give back a sense of normality to those interested in football by giving them a structure with their daily dose of football, providing them with entertainment and a diversion 
from their everyday life with the Coronavirus, as well as offering content and a platform through which they can exchange ideas with their social environment, friends, relatives, or other football fans? The latter, in particular, is of outstanding psychological and social importance concerning well-being, mood, and communication, especially in times of social distancing. Therefore, we want to illustrate these two perspectives through exemplary creative actions on the part of the TV broadcasting media and Bundesliga clubs. Thus, we focus especially on the social importance for spectators and fans and took a look at how new forms of sports coverage make it possible for them to interact with sports media, sports organizations, and other fans. Finally, we discuss the extent to which these actions represent new, innovative possibilities for sports communication in the post Coronavirus era and whether they are here to stay.

\section{Turning Old Into New: TV Broadcasters as Innovators}

With the beloved structure of weekly Bundesliga matches gone, German TV broadcasters were trying to emulate the tournament and matchday structure that their audience would normally enjoy in the spring. They were thus essentially rebuilding a structure that collapsed and devising creative methods to provide coverage of Germany's favorite sport.

Sportschau, Germany's oldest TV sports program, which has been around since before the Bundesliga began and is a building block of weekend sports reporting, fed their viewers' need for football by going deep into the archives. They offered re-live programming; that is, they broadcasted historical matches from World Cup tournaments and the DFB-Pokal. They did so either via streaming on their website or on live TV, in most cases showing matches in full. When looking at their selection of matches, the teams and decades differed, but there is one thing all of them had in common: drama. The World Cup matches mostly featured emotional German wins, such as in the 1974 final against the Netherlands or the 2014 final against Argentina. The 2014 final was even shown as scheduled programming on Easter on TV in the early evening, thus making this match available to a potentially large audience to placate the German football soul (Sportschau, 2020).

However, while fans generally appreciated these matches, as can be seen in their social media response, there was also criticism, for instance, that always watching the Germans win the World Cup games is simply boring. As scholars of sport communication, we can relate to the feeling that, even if these matches are intense highlights of German football history, always watching wins takes away the very last ounce of suspense, and watching sports becomes more of a relaxation exercise without the customary racing heart. Is that what we want from sports? Or, in the reverse, does this mean that suspense is not a crucial factor anymore and that historical matches may serve a different function, that is, escapism, with the calming effect of knowing what is going to happen, not unlike watching a movie over and over again? Taking German viewers as a judge, we can see that they seemed to be content with what daily newspaper Der Tagesspiegel called a drug replacement, as between 1.2 and 1.8 million people (out of 83 million Germans) watched the matches that were shown on live TV (Ehrenberg, 2020, para. 4). Even though these ratings are not even close to those 
for live coverage, they are nevertheless impressive for year-old matches (Niemeier, 2020, para. 2).

Regional TV broadcasters also offered re-live matches via stream, for example, Northern German broadcasting house Norddeutscher Rundfunk, who showed historical matches from DFB-Pokal and European tournaments, focusing on regional teams. Norddeutscher Rundfunk also showed iconic matches that are not of national interest but may be deeply ingrained in local history, for example Uwe Seeler's final football match. As Norddeutscher Rundfunk said on Twitter, they "beamed" their audience into 1972 (NDR Sport, 2020), including all pre- and postmatch reporting, praising Germany's former captain and a beloved icon of Hamburger Sportverein. Other regional TV broadcasters also aired regional matches, such as Bayerischer Rundfunk with Bavarian teams. Overall, these relive matches let fans celebrate triumphs from the past and served a function of escapism and entertainment by presenting what are thought to be emotional highlights of German football history.

Sports broadcaster $S k y$ went one step further and tried to emulate whole Bundesliga matchdays as they would have taken place without the Coronavirus. They remodeled their main product for football coverage, the Konferenz, which is comparable with conference switching, as moderators switch back and forth between running matches. Starting on April 4, 2020, Sky started this format by showing historical matches, not unlike Sportschau, but, in this case, with the teams that would have played against each other according to the original pre-Coronavirus matchday. Thus, Sky came as close as one can get to recreating the original matchday.

As Sky said on their website, providing their very popular Konferenz as usual to their audience was of high importance to them. Thus, they also offered their customary pre- and postmatch reporting, including a fictional results table (Sky Sport, 2020, para. 3-4). Moreover, to add to the feeling of familiarity, the historical commentary was cast aside, and current Sky commentators narrated the old matches, creating an air of a live event, even though the matches might have happened a decade ago. Thus, Sky provided their audience an almost perfect illusion by making the most of the old material. Sky's adding of new commentary to old games is similar to the "plausible live approach," as this technique allows studio producers "to re-package a taped competition in order to enhance its excitement" (Rivenburgh, 2002, p. 37). This technique is used, for example, if the broadcasting takes place with a time delay. Unlike the Sky's historical Konferenz, the plausible live version uses original sound and commentary, which are also edited to create more tension. In the United States, this approach led to criticism, as viewers sometimes did not notice that the broadcasts were manipulated. In contrast, however, German viewers were aware that Sky was presenting old games, even if the commentary was newly recorded-because of indicators such as low visual quality, retired players on the field, and old-fashioned jerseys. Nevertheless, similar to the plausible live approach, the effect may be that matches are less entertaining if viewers know that the competition is already finished. Sky went on with this programming until the Bundesliga started again on May $16,2020$.

One may ask whether recreating a matchday this meticulously with old material is too much - and whether such treatment of old matches is not only an illusion, but 
also a delusion for the fan. The drug replacement metaphor might ring even more suitable for this format than for showing historical World Cup matches, as an expensive production is made out of something that is, in the end, purely fictional. Low ratings demonstrate that only a fraction of the fans were willing to buy into the experience of the historical Konferenz (Niemeier, 2020, para. 1).

But, by keeping as close to normally scheduled programming as possible, Sky gave fans a structured Saturday and a perfect escape from unpleasant Coronavirus reality. Thus, who are we to denounce this format as a delusion, as it keeps its promise to entertain innovatively? After all, even though the ratings were low compared with Sky's live programming, some fans commented on the matches on Twitter as they would do during a normal matchday, showing their investment. Their comments ranged from match commentary to sharing memories and relishing in seeing some beloved and now retired players on the field, showing vividly how these fans were part of the emotional rollercoaster, even though many of them knew how the match would end. Moreover, even the term for this type of programming promises such emotion: re-live is a play of words on live, as in live programming, and reliving, as, in this case, reliving emotions.

In summary, showing historical matches might have its critics due to a lack of variety, but it is the drama and excitement that still made these matches worthwhile for the audience.

\section{New Ways to Go: Clubs Go Virtual}

German football clubs also tried to offer their fans some football stories and structure with their own coverage during the Coronavirus crisis. As their usual match coverage on their websites and social media fell away, they made use of creative methods to keep their followers close.

Many Bundesliga clubs took part in the Bundesliga Home Challenge (notably missing: serial Bundesliga champion FC Bayern Munich), which was conducted by the Deutsche Fußball Liga (DFL). ${ }^{1}$ In this challenge, the matchdays were emulated via videogame FIFA20, and many of the original fixtures were recreated virtually. Between March 28 and April 19, that is, for four matchdays, clubs and $D F L$ were working together on this innovative project. The rules were simple: every match lasted for roughly $25 \mathrm{~min}$ and all contestants used a PlayStation 4 playing in a mode in which all teams were equally strong (Bundesliga.com, 2020, para. 3). The Bundesliga Home Challenge mostly relied on word of mouth on social media and, thus, firmly remained in the online world, addressing a mainly young audience with an affinity for gaming.

The creative potential of the Bundesliga Home Challenge lies in at least three factors. First, the platform that was used, FIFA20, caters to the habits of a young audience that is used to streaming and, quite possibly, also plays virtual football games. Those being familiar with the game found similar features of FIFA20 replicated in the Bundesliga Home Challenge, such as scoring high numbers of goals that are unlikely in the real world. In addition to these features, one could see the jubilance and disappointment of the two contestants, as they were continually filmed during their matches. This brought a communal feeling and live emotions to the viewing experience, as the contestants, unsurprisingly, reacted in a way that is 
familiar to anyone who ever held a controller in their hands. Fans took part in conveying their own emotions via YouTube's chat function, while a live commentator narrated what was happening on-screen.

Second, this format included current Bundesliga players and two referees as contestants, giving the challenge popular faces, as well as players from the Bundesliga clubs' eSports divisions. Thus, this type of coverage can be regarded as an effort to support eSports, which enjoys rather little popularity in Germany as of now. The Bundesliga and eSports worlds were also brought together via the platforms on which the Bundesliga Home Challenge was shown, which were the DFL's website, YouTube channels of the DFL, Sky, and tabloid newspaper BILD, and also on www.esports.com and several Twitch channels, the latter two being popular websites for e-gaming and streaming. Thus, the Bundesliga Home Challenge can be regarded as innovative insofar that it normalized the presence of eSports players almost in passing.

Third, the challenge was accompanied by coverage that resembled those on normal matches, including, for example, match reporting on the $D F L$ Twitter account Virtual Bundesliga (vbl_official) and short interviews with contestants. Moreover, the clubs covered these events, and while some clubs engaged in this more than others, one can attest to a willingness to support this challenge and its visibility. FC Schalke 04, for example, provided detailed match reports on their website. Thus, despite its innovative setup as a virtual challenge, this format also catered to fans' habits by offering coverage as usual. What is of note here is that especially young fans were addressed with this challenge. But this does not mean that older fans were not participating, as could be seen on Twitter, where losses and wins were also commented on by fans who were not part of that age bracket. The Bundesliga Home Challenge was also reported on by independent news outlets; however, there was no continuous coverage.

When compared with other streaming events, the views remained low. On Sky's YouTube channel, for example, the clicks ranged between 23,000 and 45,000 per video (as of May 26, 2020). However, as the matches were shown on a plethora of platforms, views are likely to be dispersed across those, and a reliable assessment of the overall popularity of the Bundesliga Home Challenge is not possible.

All in all, like the TV broadcasters, the DFL and clubs made several efforts to recreate the Bundesliga experience, offering some kind of stability to the fans. This stability was evident in keeping to original fixtures, in the contestants, namely, the players of the respective clubs, and also in the fact that fans could even bet on the outcome of the matches. Even though the numbers of comments and views are not even close to those for real football matches, one can see that the fans were indeed engaged in this type of coverage, as wins were celebrated and losses mourned, just like they would have been for real matches. It is notable that no sponsorship deals were visible during streaming, giving the Bundesliga Home Challenge an air of a game between friends and not of a nationwide campaign. Hence, a social component was offered that is important to eSports fans (Brown, Billings, Murphy, \& Puesan, 2018, p. 429). This shows that, even though the matches were virtual, they held emotional value, especially to those football fans who are also engaged in eSports. Besides that, the Bundesliga Home Challenge was successful at bringing football fans and gamers together through choosing 
FIFA20 as the gaming platform, as a large proportion of German FIFA gamers also regularly watch football (Fritz, Preuss, Schubert, \& Liebscher, 2017, p. 273).

The future of this format is uncertain, but even though Bundesliga players would probably not be involved to such an extent in future events, which results in a loss of appeal to a bigger audience, eSports fans can turn to the Virtual Bundesliga Club Championship. It is unclear whether the Bundesliga Home Challenge helped this virtual championship to gain greater popularity in Germany outside its usual audience.

One can attest that clubs tried to make the best of the crisis-but always with the outlook that their predicament is only temporary. Thus, it remains to be seen which types of content will stay-whether we will see another virtual Bundesliga challenge in a similar format, for example-or whether the innovative content strategies will cease. While there is no need to recreate a matchday when there is real one, aspects of these creative efforts could go on, such as the involvement of real sports and eSports.

\section{No Substitution for Live Football: The Days of Creativity Are Numbered}

Whether it be broadcasting historical matches or emulating matchdays on FIFA20, many of these actions gave back the familiar structure to many football fans in a creative way. Historic duels in championship matches or legendary games at major sporting events have provided entertainment, emotions, and diversion from everyday life in the Coronavirus crisis. They have made it possible to revel in good old football times, especially as TV broadcasters chose highly emotional and dramatic matches from the past. Media and journalists, but also clubs and sports stars, have managed to offer football without football.

The cases selected here, such as the re-live matches and the simulation of the normal running competition structure, show the creative approach of journalists and reporters in a time without football. With their creative ideas, they have succeeded in offering viewers their usual structure of daily football, for example, by improvising the current matchday and motivating viewers to interact on social media and stimulate a shared fan experience. The clubs have also demonstrated the potential to create a sense of community or to maintain the connection to the club, even in these times. Particularly, social media served as a platform for communicating innovative ideas, such as challenges and actions. In this way, they stayed in touch with fans and let the football community participate in them.

A drop of bitterness may be that all those fans who are not (or no longer) involved in social media or streaming have benefited less from these online activities. Especially, older people, typically a large sports audience, have been excluded. Moreover, it is questionable whether the actions have not led too quickly to a saturation of challenges and join-in actions, as social media actions are usually short-lived and repeat themselves in a similar form over and over again. That is why we suspect that the longing for real football and classicos is not so easy to replace after all. After all, unlike daily live coverage, not everyone is ultimately interested in past matches, however thrilling they may once have been or dramatic they still might be, as the outcome is already known and may lie far in the past. 
Maybe in 15 years, we may look back to the present day and remember how the Coronavirus paralyzed the entire sports world. Perhaps we will no longer think about these creative actions and contents born out of necessity in the time without football, as, despite all creativity, they were a less emotional replacement and had not the same effects as live broadcasts of matches. Certainly, new formats satisfied the needs of the football enthusiasts for relaxation, diversion, or pastime and also conveyed a sense of normality. However, most of them were quite artificial, as in the case of Sky going to considerable lengths to offer the illusion of ongoing matchdays - but still better than nothing. Therefore, we assume that what will be remembered is rather what we have missed during the time of the Coronavirus crisis, namely, actively doing sports with our peer group, participating in competitions as athletes or spectators, meeting like-minded people in sports clubs, going to the stadium or sports bars with friends, or just talking about sports.

From the perspective of sports communication research, the period of the Coronavirus crisis has shown more clearly than ever how important sports is for society. Without sports, an important part of everyday life is missing, and the economy, jobs, and leisure activities are also severely impaired. Consequently, both the potential and the importance of sports communication research have become even more obvious during the Coronavirus crisis.

Let us finally look into the near (football) future positively. At some point, the day will come when we will go back to the stadiums together with thousands of fans to cheer on our favorite team. We will again have the feeling of being a part of this big football community, with whom we mourn a defeat and celebrate a victory euphorically - all of that, face-to-face and close together in a stadium or a bar. We will feel Schadenfreude when less beloved teams lose and get angry about referees' decisions. We will philosophize with the neighbor about missed goal chances or transfer rumors, and we will watch the summary of the matchday in a relaxed manner on Saturday evening. During all this, we will be accompanied by the media, who may continue to make use of the innovative formats they employed during the Coronavirus crisis. We, two football-crazy researchers from Germany, are looking forward to the next European Championship and the World Cup, and we will-like many other people in the world-keep our fingers crossed for our national team and feel the global spirit of football. And yet, we hope that Gary Lineker will be rightand we say that tongue-in-cheek - when he says: "Football is a simple game; 22 men chase a ball for 90 minutes and at the end, the Germans always win."

\section{Note}

1. The DFL organizes and markets the men's Bundesliga and the second Bundesliga, as well as the Virtual Bundesliga, as an eSports league.

\section{References}

Brown, K.A., Billings, A.C., Murphy, B., \& Puesan, L. (2018). Intersections of fandom in the age of interactive media. Communication \& Sport, 6(4), 418-435. doi:10.1177/ 2167479517727286 
Bundesliga.com. (2020). Rückblick auf die Bundesliga home challenge [Review of the Bundesliga home challenge]. Retrieved from https://www.bundesliga.com/de/ bundesliga/news/dfl-efootball-turnier-virtual-26-clubs-fifa-20-ea-sports-livestream-10665

Dixon, K. (2014). The football fan and the pub: An enduring relationship. International Review for the Sociology of Sport, 49(3-4), 382-399. doi:10.1177/1012690213501500

Ehrenberg, M. (2020, April 13). Fußball aus der Konserve [Canned football]. Der Tagesspiegel. Retrieved from https://www.tagesspiegel.de/gesellschaft/medien/relive-in-der-sportschau-fussball-aus-der-konserve/25736744.html

Fritz, G., Preuss, H., Schubert, M., \& Liebscher, M. (2017, September). An analysis of consumers and stakeholders involved in the eSports ecosystem in Germany. Paper presented at 25th European Association for Sport Management (EASM) Conference, Bern, Switzerland. Abstract Retrieved from http://www.easm.net/download/2017/ An-Analysis-Of-Consumers-And-Stakeholders-Involved-In-The-eSports-EcosystemIn-Germany-.pdf

Ismer, S. (2011). Embodying the nation: Football, emotions and the construction of collective identity. Nationalities Papers. The Journal of Nationalism and Ethnicity, 39(4), 547-565. doi:10.1080/00905992.2011.582864

Kunert, J. (2019). The footy girls of Tumblr: How women found their niche in the online football fandom. Communication \& Sport. Advance online publication. doi:10.1177/ 2167479519860075

Lawrence, S., \& Crawford, G. (2019). The hyperdigitalisation of football cultures. In S. Lawrence \& G. Crawford (Eds.), Digital football cultures: Fandom, identities and resistance (pp. 1-16). London, UK: Routledge.

NDR Sport. [NDRsport]. (2020, April 17). Wir beamen uns ins Jahr 1972 - das Abschiedsspiel von Uwe \#Seeler heute Abend ab 18 Uhr im Re-Live. \#uweabschied \#hsv. [Tweet]. Retrieved from https://twitter.com/NDRsport/status/1251112924459999232

Niemeier, T. (2020, April 5). Wenig Interesse an Sport-Sendungen im Fernsehen [Little interest in sports programs on TV)]. DWDL.de. Retrieved from https://www.dwdl.de/ zahlenzentrale/77096/wenig_interesse_an_sportsendungen_im_fernsehen/

Porat, A.B. (2010). Football fandom: A bounded identification. Soccer \& Society, 11(3), 277-290. doi:10.1080/14660971003619594

Rivenburgh, N.K. (2002). The Olympic Games: Twenty-first century challenges as a global media event. Sport in Society, 5(3), 32-50.

Sanderson, J., \& Kassing, J.W. (2014). New media and the evolution of fan-athlete interaction. In A.C. Billings \& M. Hardin (Eds.), Routledge handbook of sport and new media (pp. 247-270). New York, NY: Routledge.

Sky Sport. (2020). JETZT auf Sky! Die "hisTOOORische Sky Konferenz" [Now on Sky! The historical (play on words with German word for "goal") Sky Konferenz]. Retrieved from https://sport.sky.de/fussball/artikel/historische-bundesliga-konferenzbei-sky-uebertragung-im-tv/11967242/34240

Sportschau. (2020). Re-live - Großer WM-Marathon zu Ostern [Re-live - big World Cup marathon at Easter]. Retrieved from https://www.sportschau.de/weitere/allgemein/ sportschau_history/re-live-mit-wm-marathon-100.html

Wann, D.L., Grieve, F.G., Zapalac, R.K., \& Pease, D. (2008). Motivational profiles of sport fans of different sports. Sport Marketing Quarterly, 17(1), 6-19. 